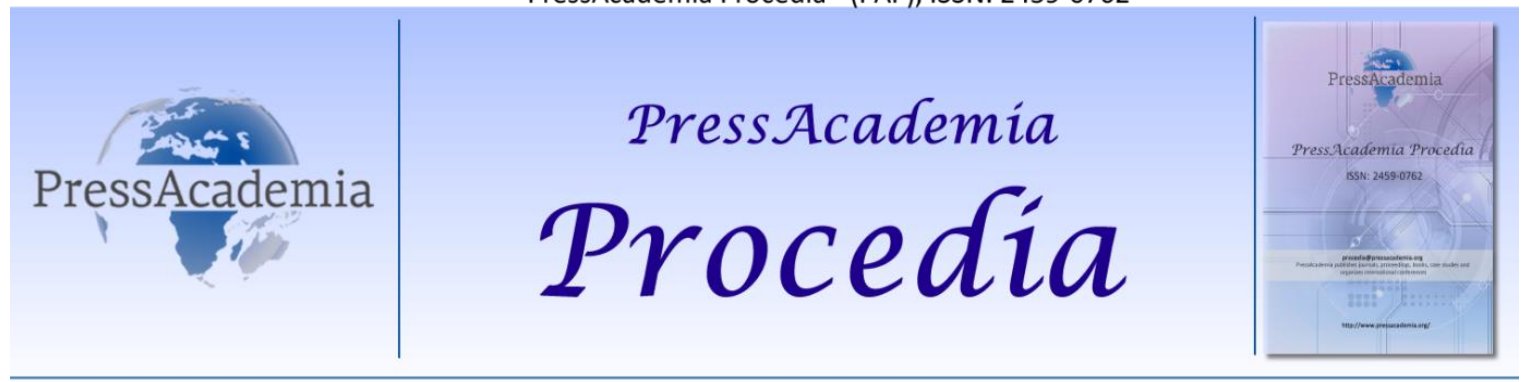

2nd World Conference on Technology, Innovation and Entrepreneurship May 12-14, 2017, Istanbul, Turkey. Edited by Sefer Şener

\title{
NEW FORESIGHT GENERATION AND FRAMEWORK OF FORESIGHT
}

\section{DOI: 10.17261/Pressacademia.2017.593 \\ PAP-WCTIE-V.5-2017(31)-p.224-233}

\author{
Nurdan Yuksel $^{1,2}$, Hasan Cifci $^{1,3}$ Serhat Cakir $^{4}$ \\ ${ }^{1}$ Department of Science and Technology Policies Studies, Middle East Technical University \\ ${ }^{3}$ Turkish Air Force \\ ${ }^{4}$ Department of Physics, Middle East Technical University, Çankaya, Ankara, Turkey \\ ${ }^{2}$ ASELSAN Inc.,Yenimahalle, Ankara, Turkey \\ *Corresponding Author: nurdan.yuksel@metu.edu.tr
}

\begin{abstract}
The article starts with various definitions of technology foresight from the literature and new definition is given by the authors. Prominent definitions of foresight are analyzed and given according to their different elements in the literature. By assessing the evolution of foresight as a term and its five generations through time, the foresight of sixth generation is set forth. Based on the literature analysis, foresight generations are grouped into four main categories. Foresight frameworks are analyzed and a generic foresight functional model with nine consecutive phases named 'FORESIGHT' is suggested. Functions in the FORESIGHT model are matched with the phases of main foresight frameworks in the literature based on their actions and artifacts within specific phases. It is like a guide for practitioners of which activities are carried out in foresight studies.
\end{abstract}

Keywords: Foresight, foresight framework, foresight generations.

\section{INTRODUCTION}

Humans have a capacity to systematize the estimation of future events [1]. Voros [2] defines the Three Laws of Future based on the suggestion of Amara [3] as it is not predetermined, not predictable and the selection of today affects its outcomes. Since the future itself is a complex subject coming from its uncertain nature, futures oriented studies are difficult to determine and realize. Any statement related with future cannot be confirmed at the time when they are built [4].

It is a challenge or almost impossible to predict the future. Following quotes show the difficulty of predicting the future developments and prove the need a new approach to the future related matters:

- "Everything that can be invented has been invented", Charles H. Duell, Commissioner, US Office of Patents, 1899.

- "Airplanes are interesting toys, but of no military value", Marshall Foch, 1911.

- "There is no reason for an individual to have a computer at home", Ken Olsen, Chairman of Digital Equipment Corporation, 1978.

Unlike future as a term, which invokes "looking ahead" [5], futures studies also include "looking back" [6] and looking present. Since futures is very wide subject, there is different terminology about it as futures research, "futures studies", sometimes futures analysis, futurism, futuristics, or even futurology [2]. According to Sardar [5], suffix of -logy in futurology which shows the meaning of certainty and objectivity is not suitable for futures having ambiguity. He mentions about the linguistic and pronunciation difficulty of futuristics and lethality of futurism's logic which implies that science will provide knowing the future. While Voros [2] prefers to use Futures since the term gives the plurality of different futures, Sardar [5] finds the best suitable term as Future Studies with the same reasoning of Voros. Futures are evaluated as extensive professional and academic area continuing 
to develop with its methods, tools and research [7]. Futures studies are multi-disciplinary, trans-disciplinary and un-disciplinary ${ }^{1}[5]$ activities for the future.

When looking at the literature, forecast and foresight as future studies come into prominence. While forecast is mainly passive attitude for the single future, foresight is systematic active attitudes of today for diverse futures. Foresight has wider aim such as involvement of broad participation, invoking the policy makers with its outputs [8] and providing greatest economic and social benefits [9]. Forecast is a set of techniques which are used to convert inputs to outputs whereas foresight is mainly a process of which techniques are used to create common understanding, commitment and networking [10]. According to Loveridge [11] foresight is structurally based on the "uncomfortable marriage of well-structured and tested information to its counterpart subjective opinion". The timeline in Figure 1 shows the history of foresight as a term.

Figure 1: Timeline of Foresight as a Term ${ }^{2}$

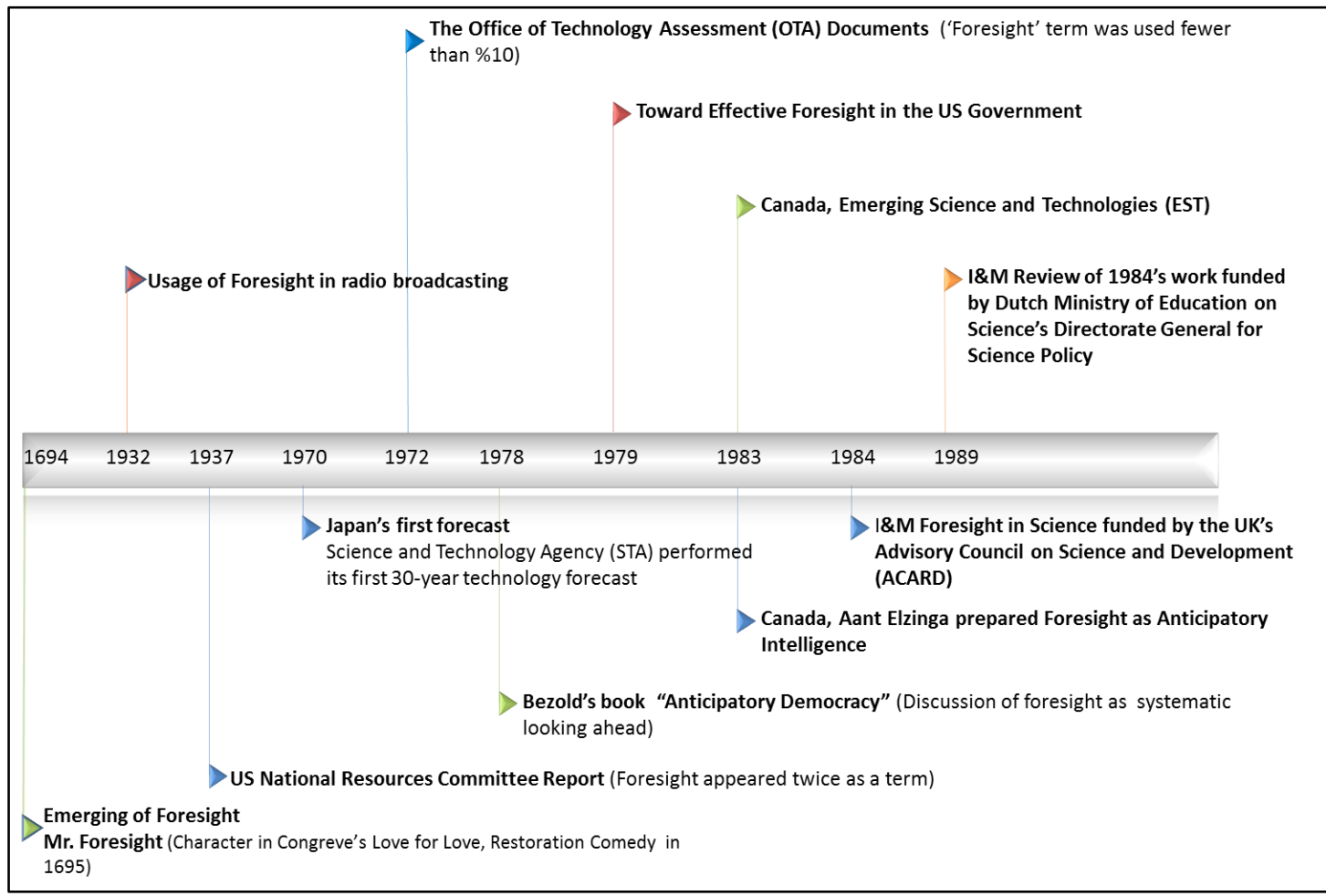

Hines and Gold [12] researched about the foresight profession and assessed its status against the common criteria of profession. Since they concluded that it corresponded the requirements of capacity, field and discipline more or less but it was not able to emerge as profession by 2013. Together with the knowledge economy in globalized world, it is undeniable that science and technology are the major determinants of the future. So, technology foresight becomes the most important type for future studies. Martin [13] defines Technology Foresight (TF) as "A process involved in systematically attempting to look into the longer-term future of science, technology, the economy and society with the aim of identifying the areas of strategic research and the emerging generic technologies likely to yield the greatest economic and social benefits". TF also creates networks between the stakeholders by invoking awareness about opportunities, threads, social and economic needs, benefits or damages. TF studies contribute to knowledge creation by building $\mathrm{Ba}^{3}$ which is shared extent of the relations emerged from interactions between individuals, groups and environment [14] and filling the $M a^{4}$ which represents the spaces between boundaries of Ba such as disconnection of stakeholders or physical distance between them.

TF is just one of the analyses of Technology Future Studies (TFA) or Future oriented Technology Analyses (FTA). Different forms of FTA, which covers emerging technology conditions and types,

\footnotetext{
${ }^{1}$ It consciously rejects the status and state of a discipline while being a fully-fledged systematic mode of critical inquiry.

${ }^{2}$ Miles [22] was used in building timeline of foresight.

${ }^{3}$ Japanese term come up with by philosopher Kitaro Nishida and developed by Shimizu

${ }^{4}$ Japanese word which can be roughly translated as "gap", "space", "pause" or "the space between two structural parts [43].
} 
technology development paths and their impacts systematically, such as technology forecasting, technology intelligence, technology assessment, technology roadmapping exist concurrently with TF [15].

In Table 1, elements of various foresight definitions in the literature are shown. Elements are listed based on the number of references given. In accordance with the model suggested in this study, a new foresight definition is set forth as follows:

"Foresight is a systematic and multidisciplinary process with proper methodology combinations for identifying technological, economic and social areas to prioritize investments and research in order to determine medium or long term future strategies by using all level of resources from organizational to international."

\section{FORESIGHT GENERATIONS}

Foresight studies can be divided into different generations based on the scope, goals and methods involved within foresight processes. In the literature, there are different approaches which can be categorized under 4 main groups towards generational models of foresight as shown in Figure 2.

Linstone [16] classifies foresight generations into three groups based on certain society.

I. First generation (ca. 1800 - Industrial Society): Foresight activities were mainly based on technology forecasting which dated back to industrial era with Taylor's scientific management. Quantitative, semiquantitative and qualitative tools were developed in order to forecast and predict technological developments.

II. Second generation (ca. 1970 - Information Society): Information technology has noteworthy impact in effecting simultaneous centralization and decentralization or globalization and localization. Computer capabilities have been used for forecasting. It has become possible to use vast majority of databases and computer power in order to reach and process huge volumes of data.

III. Third generation (ca. 2025 - Molecular Society): This era is founded on molecular level with nanotechnology, biotechnology, and materials science stepping forward. It is also referred to as the Nano-biotechnology era and the Micro and Nanotechnology era (MNT). Nanotechnology is expected to lead to a vast increase in computational power and intelligence which are exploited in foresight methods and activities. As one of the main triggers of the foresight studies, globalization plays an important role in emerging of foresight generations.

Table 1: Elements of Various Foresight Definitions

\begin{tabular}{|l|l|l|l|l|l|l|l|l|l|l|l|l|l|l|l|}
\hline & & & & & & & & & & & & \\
\end{tabular}




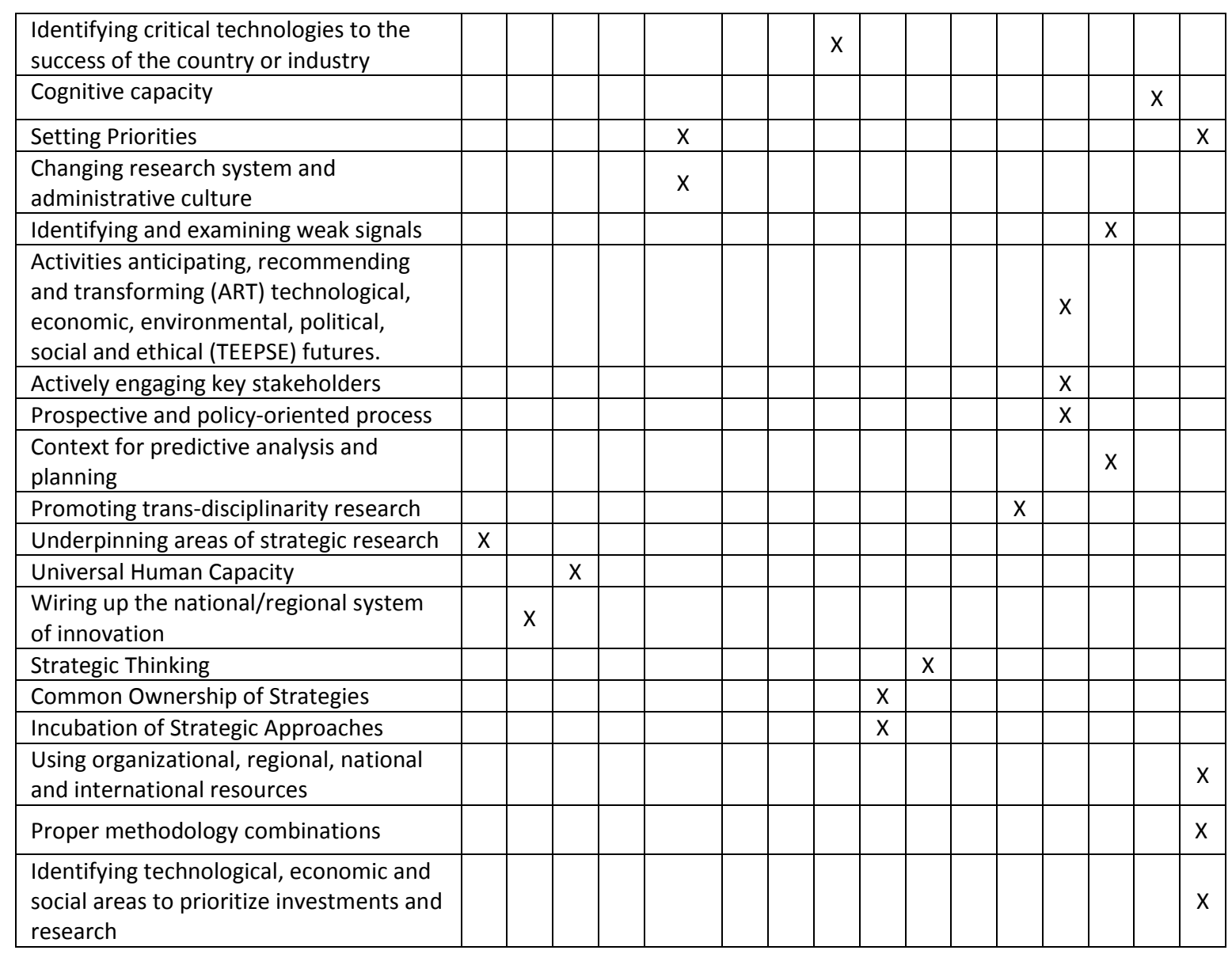

Figure 2: Main Approaches to Foresight Generations

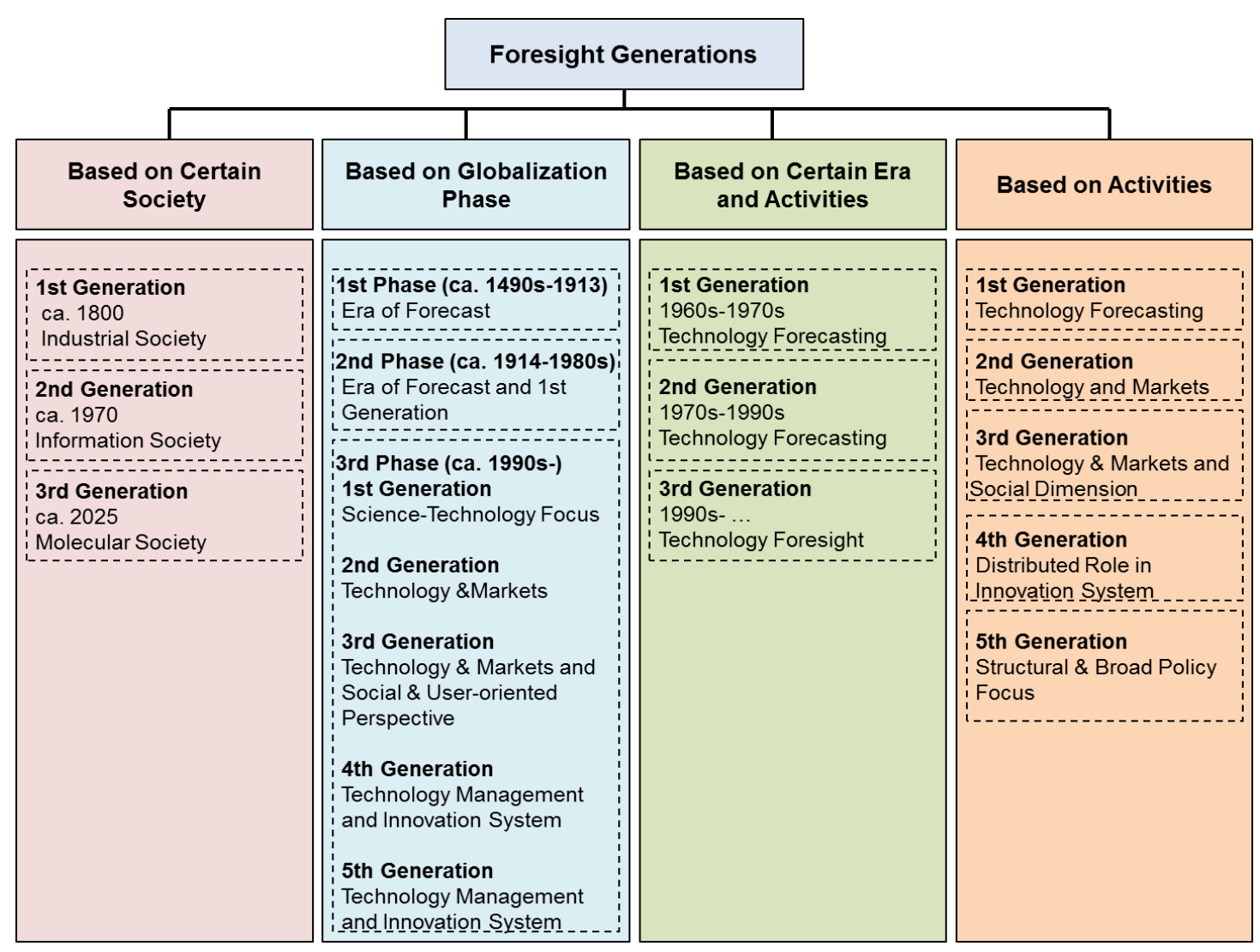


Jemala [29] classifies five foresight generations according to their corresponding three globalization phases by pointing out first foresight studies of related generations according to date:

I. First globalization phase: The phase dating back to Christopher Columbus in 1490s and lasting to 1913 with the effect of "Laissez Faire" thought was generalized as Era of Forecast since there were not so many systematic approaches and strategic plans in general. Most of the future studies were being performed just because of inherent human reaction to its fear of undetermined future.

II.Second globalization phase: The phase from 1914 to 1980 s mainly affected from world wars and information and communication technologies was named as Era of Forecast until 1956 and First Generation of Foresight from 1956 to 1990. First foresight generation focused on science and technology of post war conditions. Although 'forecasting' term continued to be used to 1980s, in 1956 China performed forecast having many features of foresight. Systematic manner with participatory methods and strategic planning to be beneficial in societies especially with the efforts of futurology and technology professionals [29], e.g. 30-year technology forecast of Japanese Science and Technology Agency (STA) in 1971, started to be dominant as First Generation of Foresight.

III.Third globalization phase: The phase from 1999 to 2009 based on the inequalities between the countries arising from the global trade and finance included all five generations of foresight. Second foresight generation was mainly triggered from industry and markets. It is performed with the participation of different stakeholders and science-technology relation with social-economic development was the main focus. Third foresight generation, approximately in 2000, expands the stakeholders to social actors to create foresight culture and to do studies on different areas like environment, education, ethics etc. apart from just science and technology. Fourth and fifth generations focus on systematic approach with system view more and technology and innovation management become dominant.

When it comes to mixed approach -i.e. generations based on certain era and activities- Reger [30] determines three generations based on technology foresight process and assigns certain time intervals per generation [31]:

I. First generation (from 1960s to beginning of 1970s): Technology foresight was carried out within organizations and focused on forecasting and prediction. Foresight was conducted as a sub-task of project planning.

II. Second generation (from 1970s to beginning of 1990s): Foresight was focusing on technology data and remained a forecasting action. Specialized and separated foresight units were responsible for foresight within organizations.

III. Third generation (from 1990s): Technology foresight became an important element of strategic management and decision-making. Not only technologic but also economic, social, environmental and legal trends were taken into account. Activities were extended to encompass networks of organizations.

In terms of foresight generations based on activities, Georghiou categorizes generations into five different groups based on the stakeholders involved and activities carried out [32]. Foresight generations are [33]:

I. First generation: Merely technology forecasting carried out by experts on the future studies. Main goals are making accurate predictions and expressing results to non-expert audiences.

II. Second generation: Foresight activities which began in 1990s in order to combine technology and markets. Industry and academia are bringing together to establish science and business networks.

III. Third generation: While keeping technology and markets, social dimension is added to the studies. Industry, academia, government and civil society are the main actors. More stakeholders are involved in evaluation.

IV. Fourth generation: Foresight activities are moved away from integrated programs to different actors within science and innovation system. Multiple organizations carry out foresight studies according to their needs with some level of coordination.

V. Fifth generation: Structural activities focusing on complex policy issues of global science, technology and innovation systems.

The foresight generations in the literature classified based on the certain dates by authors Reger [30] and Jemala [29] (with the addition of the first performing countries) is depicted in the Figure 3. While Reger [30] assorted foresight as three generations up to 2001, Jemala [29] grouped them into five generations until 2009. The generations' dates were not coherent in their studies because of different arguments used in classification and terminological confusion between forecast and foresight. An individual foresight program can have elements of more than one generation. These generations are not sequential approaches and should be thought as "concurrent, overlapping and reflexive" [34]. 
Figure 3: Dates of Foresight Generations in the Literature

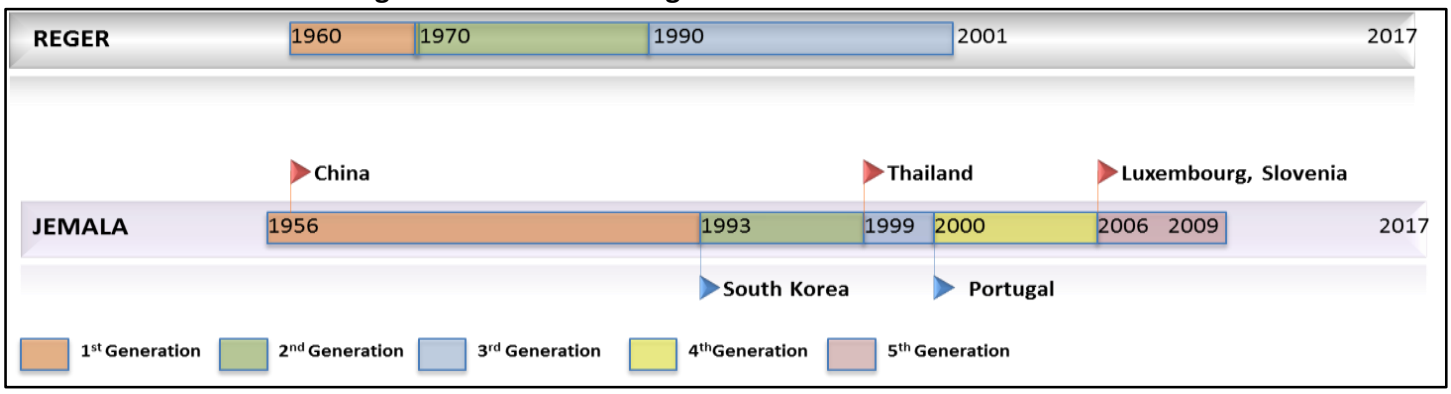

When foresight generations are evaluated for their methodologies approaches; first generation, which was dominated by forecasting mostly around 1960s, used mostly quantitative methods although some qualitative methods like scenario planning emerge in this generation [35]. For the second generation, in which foresight activities started to increase, participative methods together with qualitative methods became widespread. Third generation, which included social dimension, used the analysis like SWOT (Strengths, Weaknesses, Opportunities, and Threats) more. Fourth and fifth generations, which focus on global science, technology and innovation systems with different actors and complex structures, use mixed and internet based methods more prevalently.

Saritas [36] suggests new foresight approach which comprehends complex, inter-dependent, inter-connected nature and behaviors of the foresight system. As sixth foresight generation the assessment of the authors is added to Table 2, which is adapted from Georghiou et al. [19] and [37], and generations are shown with respect to its concentration/dimensions, participating actors, economic rationales and principle.

Table 2: Foresight Generations

\begin{tabular}{|l|l|l|l|l|}
\hline \multicolumn{1}{|c|}{$\begin{array}{c}\text { Foresight } \\
\text { Generations }\end{array}$} & $\begin{array}{c}\text { Concentration } \\
\text { Dimensions }\end{array}$ & Participating Actors & \multicolumn{1}{|c|}{$\begin{array}{c}\text { Economic } \\
\text { Rationales }\end{array}$} & \multicolumn{1}{|c|}{ Principle } \\
\hline First & Technology & $\begin{array}{l}\text { Technology Experts, } \\
\text { Professional Futurists }\end{array}$ & $\begin{array}{l}\text { Economic } \\
\text { Planning }\end{array}$ & $\begin{array}{l}\text { To follow the } \\
\text { disciplinary taxonomies } \\
\text { of science-engineering }\end{array}$ \\
\hline Second & $\begin{array}{l}\text { Technology- } \\
\text { Markets }\end{array}$ & $\begin{array}{l}\text { Academics, Industrial } \\
\text { Researchers and } \\
\text { Managers }\end{array}$ & Market Failure & $\begin{array}{l}\text { To provide a bridge } \\
\text { between } \\
\text { industrial/service sector } \\
\text { and economy }\end{array}$ \\
\hline Third & $\begin{array}{l}\text { Technology- } \\
\text { Markets-Social } \\
\text { Dimension }\end{array}$ & $\begin{array}{l}\text { More Social } \\
\text { Stakeholders (NGOs, } \\
\text { Consumer Groups }\end{array}$ & $\begin{array}{l}\text { System Failure } \\
\text { (socio-economic } \\
\text { system) }\end{array}$ & $\begin{array}{l}\text { To solve socio- } \\
\text { economic problems }\end{array}$ \\
\hline Fourth & $\begin{array}{l}\text { Science- } \\
\text { Innovation }\end{array}$ & $\begin{array}{l}\text { More Participators of } \\
\text { National Policy Exercise }\end{array}$ & $\begin{array}{l}\text { Bridging } \\
\text { institutions in } \\
\text { socio-economic } \\
\text { system }\end{array}$ & $\begin{array}{l}\text { To build own structures } \\
\text { in terms of object of } \\
\text { analysis }\end{array}$ \\
\hline Fifth & $\begin{array}{l}\text { Global science- } \\
\text { technology } \\
\text { management- } \\
\text { innovation } \\
\text { systems }\end{array}$ & $\begin{array}{l}\text { More experts, } \\
\text { stakeholders and } \\
\text { professionals with } \\
\text { foresighting skills }\end{array}$ & $\begin{array}{l}\text { Bridging } \\
\text { institutions in } \\
\text { socio-economic } \\
\text { system }\end{array}$ & $\begin{array}{l}\text { To build own structures } \\
\text { in terms of object of } \\
\text { analysis }\end{array}$ \\
\hline Sixth & $\begin{array}{l}\text { Netocracy } \\
\text { biotechnology, } \\
\text { more values and } \\
\text { ethics in chaordic } \\
\text { social dimension }\end{array}$ & $\begin{array}{l}\text { Netocrats } \\
\text { (crowd-sourced from a } \\
\text { much wider range of } \\
\text { constituencies than the } \\
\text { usual experts), } \\
\text { Futurists, Futurizens }\end{array}$ & $\begin{array}{l}\text { Blurring the roles } \\
\text { of consumers and } \\
\text { producers in } \\
\text { economy }\end{array}$ & $\begin{array}{l}\text { To co-create by } \\
\text { combining altogether } \\
\text { the desirable visions of } \\
\text { stakeholders with } \\
\text { evidence from big data }\end{array}$ \\
\hline
\end{tabular}

\footnotetext{
${ }^{5}$ "It refers to a perceived global upper-class that bases its power on a technological advantage and networking skills" [44].

6 "Those who can harness networks of information and master new forms of communication will control finance and legislation, forming the new business and government elites" [45]

7 "People online who actively contribute towards the development of the Net (a Net Citizen)" [46].

8 "Prescient, future-facing, forward-looking people, citizens of future [47] and futurium (The European Commission Project collecting people's contributions in futures policy constitution) community.
} 


\section{FORESIGHT FRAMEWORKS AND PRINCIPLES}

The main dimensions of foresight, which are context, scope, artifacts, participating actors and methods, have evolved throughout the foresight journey within its generations until today. So, many scholars have been contemplating about foresight's theoretical and conceptual framework to catch this dimensional change. It has also brought the need for common vocabulary for foresight thus ontology has become important. "Ontology is a formal, explicit specification of a shared conceptualization" [38] and it provides clarification of knowledge [39]. Within this perspective, in the foresight literature, frameworks play important role to create common terminology. Accordingly, some of well-known foresight frameworks are analyzed in the following paragraphs.

Martin [13] analyses foresight as a process having three phases. In the first phase named pre-foresight, the decision taking to perform the process and preparation are the main steps. Second phase is foresight containing comprehensive design, strategic analysis of its possible utilities, consensus about the best promising options, determining the scientific priorities by disseminating the outputs. In the last phase which is post-foresight, implementation of foresight in policy-making and resources allocation take place [39].

Voros [40] defined generic foresight framework by treating it as a process. His framework is based on modification of Horton's three phased process, combining it with Mintzberg's strategy view and Slaughter's strategic foresight approach. While knowledge gathering and strategic intelligence are assessed as inputs; analysis which is related to the question of 'what seems to be happening?', interpretation based on the question of 'what is really happening?' and prospection related to the 'what might happen?' are handled in the foresight phase. Outputs are comprised of strategic choices resulted from broad understanding. By separating outputs and action, he added strategy as a last step that contains actions for decision-making in strategy development and strategy planning.

Hines \& Bishop [41] viewed foresight as a process requiring six involvements of leaders and organizations defined as framing, scanning, forecasting, visioning, planning and action. Framing contains problem identification and determination of its and its solutions' expenses. Scanning is the step of being aware of the trends and related information. While forecasting is creating the possible futures, visioning is selection of desired future and determining the position of organization for that future. Planning is generating the road to the desired future and acting is bringing plans to actions on ongoing base.

Saritas [36] proposed a Systemic Foresight Methodology (SFM) comprised of Intelligence, Imagination, Integration, Interpretation, Intervention and Impact, all within Interaction, to generate and conduct foresight operations. All of the operations are performed in dynamic, repetitive and evolutionary way and considered in the extent of how systems in the range of foresight are handled. Foresight is implemented with the thought of the internal (e.g. management, processes, motivation, politics, culture, power, skills) and external context (e.g. STEEPV ${ }^{9}$ ) in the systemic approach [36]. The systemic approach assesses the foresight with its interrelated and interdependent elements and their complex connections [36]. Within this approach, intelligence phase contains gathering data, analysis of trends and changes to determine the scope and content of the foresight study. Imagination involves creating and interconnecting new ideas, scenarios. Integration is the phase of identifying priorities and creating agreed model of future. While the models and visions are transformed to strategies to be carried out in interpretation phase, plans and policies are required to be constituted in order to put them into practice in intervention phase. The foresight is reviewed and lessons learned are taken to renew it or for better applications in impact analysis. All of the phases in SFM are conducted with the participation of stakeholders in some forms interaction.

Schultz [42] took foresight as an integrated process and defined it as a five key activities namely 'identify and monitor change', 'assess and critique impacts', 'imagine alternative outcomes', 'envision preferred vision' and 'plan and implement change' in order. He puts the change to the center of foresight process and starts with catching the pattern of change with trend analysis. As a second activity, the impacts of change are defined by sorting them according to their relevance and importance. Determining alternative futures and picturing them in the mind is the key element called imagining alternative outcomes. Selecting the desired future and putting it forth as stated vision is the following activity. Last activity is comprised of specifying stakeholders, designating resources for the clear purposes, developing strategies, organizing activities and creating change.

With the light of the foresight frameworks in the literature, in this study a generic foresight functional model named 'FORESIGHT' which is built to draw outlines of the functional system is developed. When one of the functions doesn't work properly, it can't be mentioned about the proper operation of the whole system. In the proposed functional model FORESIGHT, there are nine functional blocks as 'framing', 'obtaining', 'reviewing', 'establishing', 'synthesizing', 'illustrating', 'guiding', 'handling' and 'tracking'. In the model, consecutive functions are interrelated and interdependent.

\footnotetext{
${ }^{9}$ STEEPV: Social, Technological, Economic, Ecological, Political, Values analysis tool is a framework to gauge how the external
} environment will impact a given company's strategic plan to remain competitive. 
Framing: Fulfilling the tasks of determining foresight purpose, scope, content and time horizon.

Obtaining: Collecting data and information, gathering participants also by using co-nomination in iterative way which are consistent with its frame stated in the previous function.

Reviewing: Sharing ideas and opinions on the accessed data and information related with past and present, summarizing, analyzing them to be processed.

Establishing: Thinking about the future with the knowledge created, picturing possibilities in the minds and imagining the alternatives to create futures.

Synthesizing: Combining all alternative future thoughts with the present state conditions and resources in an interpretive way. Discussion, negotiation, facilitation and conflict resolution takes place in this function.

Illustrating: Pointing out the possible futures, visioning and generating reports, broadcasting with multimedia, sharing in social media.

Guiding: Defining actions and changes those will be performed, determining sequencing of them to reach different futures, strategy development and planning.

Handling: Taking actions, making changes and solving application problems.

Tracking: Evaluating outcomes and results of handling, performing impact analysis to take lessons for learning process.

In Table 3, functions in the FORESIGHT have been matched with the phases of mentioned foresight frameworks based on their actions and artifacts within specific phases.

Table 3: Foresight Frameworks in the Literature

\begin{tabular}{|c|c|c|c|c|c|c|c|}
\hline & $\begin{array}{c}\text { Yüksel\&Çifci } \\
\text { (2017) } \\
\end{array}$ & Martin (1995) & Miles (2002) & Voros (2003) & $\begin{array}{c}\text { Bishop\&Hines } \\
\text { (2006) }\end{array}$ & Schultz (2006) & Sarıtaş (2011) \\
\hline & $\begin{array}{l}\text { Foresight } \\
\text { Functions } \\
\end{array}$ & Foresight Process & $\begin{array}{c}\text { The Foresight } \\
\text { Cycle }\end{array}$ & $\begin{array}{l}\text { A Generic } \\
\text { Foresight }\end{array}$ & $\begin{array}{c}\text { Framework } \\
\text { Foresight }\end{array}$ & $\begin{array}{c}\text { Key Activities of } \\
\text { Integrated Foresight }\end{array}$ & $\begin{array}{l}\text { Systemic } \\
\text { Foresight }\end{array}$ \\
\hline $\mathbf{F}$ & Framing & \multirow{2}{*}{$\begin{array}{l}\text { Pre-Foresight (Decision, } \\
\text { Preparation) }\end{array}$} & Pre-Foresight & \multirow{2}{*}{ Inputs } & Framing & & \\
\hline 0 & Obtaining & & Recruitment & & \multirow{2}{*}{ Scanning } & $\begin{array}{c}\text { Identify and monitor } \\
\text { change }\end{array}$ & Intelligence \\
\hline $\mathbf{R}$ & Reviewing & \multirow{5}{*}{$\begin{array}{c}\text { Foresight (Process Design, } \\
\text { Strategic Analysis, } \\
\text { Agreeing, Disseminating) }\end{array}$} & \multirow{5}{*}{ Generation } & \begin{tabular}{|c|} 
Analysis \\
Interpretation \\
\end{tabular} & & \begin{tabular}{|c|}
$\begin{array}{c}\text { Asses and Critique } \\
\text { Impacts }\end{array}$ \\
\end{tabular} & Imagination \\
\hline E & Establishing & & & & & Envision Preferred & Integration \\
\hline $\mathbf{S}$ & Sythesizing & & & Prospection & Forecastıng & Futures & Interpretation \\
\hline I & Illustrating & & & Outputs & \multirow{2}{*}{$\begin{array}{l}\text { Visioning } \\
\text { Planning }\end{array}$} & & \\
\hline G & Guiding & & & \multirow{2}{*}{ Strategy } & & \multirow{2}{*}{$\begin{array}{c}\text { Plan and Implement } \\
\text { Change }\end{array}$} & \multirow{2}{*}{ Intervention } \\
\hline H & Handling & $\begin{array}{c}\text { Post-Foresight } \\
\text { (Implemantation, Allocation) }\end{array}$ & Action & & Action & & \\
\hline $\mathbf{T}$ & Tracking & & Renewal & & & & Impact \\
\hline
\end{tabular}

\section{CONCLUSION}

Future has always been wondered and some systematic studies have been done to get ready to different futures through the time. So, there are different futures studies in the literature including the foresight which is the most common one especially from 1990s. To cover the all elements of prominent foresight definitions in the literature, the new definition of foresight which is based on the resources, methodology and futures strategies is presented. By searching the literature for foresight generations, sixth foresight generation is evaluated as the one dominated with netocracy and biotechnology.

It is assessed that the intensive use of big data, Internet of Things, add on biological units and artificial cyborgs will bring ethical and social dimensions together. The sixth generation foresight studies involve the netocrats, netizens, futurists and futurizens as the actors who initiate, carry out the operations and affected from them.

Additionally, a generic foresight functional model with nine consecutive phases named FORESIGHT (Framing, Obtaining, Reviewing, Establishing, Synthesizing, Illustrating, Guiding, Handling, Tracking) is suggested with the search of frameworks in the literature. This functional model covers the phases of a generic foresight process regarding to its activities done.

Futures will continue to remain the latent area always been tampered by humans even the science allows to read 
the thoughts and determine the people tendencies in the future. The combination of these different thoughts and tendencies is incredible process, which is also affected by diverse factors, and creates ambiguity. In contrast to this uncertainty for futures, foresight is improvable area and can be made more explicit and useful by using diverse resources, effective methodology based on new advanced techniques and by constituting strategies meticulously for alternative futures. Foresight can become more effective and successful by applying its evaluation and impact analysis; executing it iteratively and treating it as learning process. Nevertheless, the nature of the partiality of futures -the impossibility of comprehension- will remain the most important limitation of foresight process.

\section{REFERENCES}

[1] J. Schatzmann, R. Schäfer, and F. Eichelbaum, "Foresight 2.0 - Definition, overview \&amp; evaluation," Eur. J. Futur. Res., vol. 1, no. 1, p. 15, 2013.

[2] J. Voros, “A Primer on Futures Studies," Prospect Foresight Bull., vol. 6, no. 1, 2001.

[3] R. Amara, "The Futures Field: Searching for Definitions and Boundaries," Futurist, vol. 15, no. 1, pp. 25-29, 1981.

[4] P. R. Kreibich, B. Oertel, and M. Wölk, "Futures Studies and Future-oriented Technology Analysis Principles, Methodology and Research Questions," in Berlin Symposium on Internet and Society, 2011, pp. 1-53.

[5] Z. Sardar, "The Namesake: Futures; futures studies; futurology; futuristic; foresight-What's in a name?," Futures, vol. 42, no. 3, pp. 177-184, 2010.

[6] R. A. Slaughter, The Foresight Principle: Cultural Recovery in the 21st Century. London: Adamantine Press, 1995.

[7] M. Conway, Foresight: an Introduction. Thinking Futures, 2015.

[8] G. Steed and S. Tiffin, "A National Consultation on Emerging Technology," in Science Council of Canada, 1986.

[9] B. R. Martin, “The origins of the concept of 'foresight' in science and technology: An insider's perspective," Technol. Forecast. Soc. Change, vol. 77, no. 9, pp. 1438-1447, 2010.

[10] K. Cuhls, "From forecasting to foresight processes-new participative foresight activities in Germany.," Forecast, vol. 22, pp. 93-111, 2003.

[11] D. Loveridge, "Technology foresight and models of the future," in CEC ASTPP Network Conference Ideas in Progress, 1996, no. Number 4.

[12] A. Hines and J. Gold, "Professionalizing foresight: Why do it, where it stands, and what needs to be done," J. Futur. Stud., vol. 17, no. 4, pp. 35-54, 2013.

[13] B. R. Martin, "Foresight in science and technology," Technol. Anal. Strateg. Manag., vol. 7, no. 2, pp. 139-168, 1995.

[14] I. Nonaka and N. Konno, "The concept of 'Ba': BUILDING A FOUNDATION FOR KNOWLEDGE CREATION," Calif. Manage. Rev., vol. 40, no. 3, pp. 40-54, 1998.

[15] V. Kamtsiou, A. Naeve, L. K. Stergioulas, and T. Koskinen, "Roadmapping as a Knowledge Creation Process: The PROLEARN Roadmap," J. Knowl. Manag., vol. 1, no. 3, pp. 163-173, 2006.

[16] H. A. Linstone, "Three eras of technology foresight," Technovation, vol. 31, no. 2-3, pp. 69-76, 2011

[17] B. R. Martin and R. Johnston, "Technology Foresight for Wiring Up the National Innovation System-Experiences in Britain, Australia, and New Zealand," Technol. Forecast. Soc. Change, vol. 60, no. 1, pp. 37-54, 1999.

[18] L. Georghiou, "The UK Technology Foresight Programme," Futures, vol. 28, no. 4, pp. 359-377, 1996.

[19] L. Georghiou, J. C. Harper, M. Keenan, I. Miles, and R. Popper, The Handbook of Technology Foresight: Concepts and Practice. Cheltenham, UK: Edward Elgar Publishing, Inc., 2008.

[20] R. Barré, "Synthesis of Technology Foresight, Strategic Policy Intelligence: Current Trends, the state of Play and Perspectives," 2001.

[21] I. Miles and M. Keenan, "Practical Guide To Regional Foresight in the UK," 2002.

[22] I. Miles, "The development of technology foresight: A review," Technol. Forecast. Soc. Change, vol. 77, no. 9, pp. 1448-1456, 2010

[23] J. C. Harper, "Vision Document, eFORESEE Malta ICT and Knowledge Futures Pilot, 2003." 2003.

[24] J. Voros, “A generalised 'layered methodology' framework," Foresight J. Futur. Stud. Strateg. Think. Policy, vol. 7, no. 2, pp. 28-40, 2005

[25] M. Keenan, R. Popper, M. Alexandrova, D. Marinova, D. Tchonkova, and A. Havas, "Research infrastructures foresight (rif)," 2007.

[26] R. Popper, “Foresight Methodology : an overview and more..." 2008. 
[27] R. Popper, “Dr. Popper's Foresight and Horizon Scanning Blog-Futures.” 2011.

[28] J. M. Schmidt, "Policy, planning, intelligence and foresight in government organizations," Foresight, vol. 17, no. 5, pp. 489-511, 2015.

[29] M. Jemala, "Evolution of foresight in the global historical context," Foresight, vol. 12, no. 4, pp. 65-81, 2010.

[30] G. Reger, "Technology Foresight in Companies: From an Indicator to a Network and Process Perspective," Technol. Anal. Strateg. Manag., vol. 13, no. 4, pp. 533-553, 2001.

[31] R. Boutellier, U. Deplazes, and K. Loffler, "Model of Technology Foresight: An innovative Approach," in IEEE International Engineering Management Conference, 2007, pp. 7-14.

[32] L. Georghiou and M. Keenan, "Evaluation of national foresight activities: Assessing rationale, process and impact," Technol. Forecast. Soc. Change, vol. 73, no. 7, pp. 761-777, 2006.

[33] R. Popper, L. Georghiou, M. Keenan, and I. Miles, Evaluating Foresight Fully-Fledged Evaluation of the Colombian Technology Foresight (CTFP). Universidad del Valle (Colombia), 2010.

[34] S. Gieseke, "FLA as a means of participation in modern democratic decision-making," in The Role of Forward-Looking Activities for the Governance of Grand Challenges, Insights from the European Foresight Platform, 2012.

[35] M. Conway, "An Overview of Foresight Methodologies," Thinking Futures. pp. 1-10, 2006.

[36] O. Saritas, "Sytemic Foresight Methodology," in Forth International Seville Conference on Future-Oriented Technology Analysis (FTA) FTA and Grand Societal Challenges - Shaping and Driving Structural and Systemic Transformations, 2011, p. 34

[37] J. C. Harper, "Impact of Technology Foresight," 2013.

[38] R. Studer, R. Benjamins, and D. Fensel, "Knowledge engineering: Principles and methods," Data Knowl. Eng., vol. 25, no. 1-2, pp. 161-198, 1998.

[39] A. Abdollahi, M. Fasanghari, M. Mohammedpour, M. Soltani, and M. Nili, “An Ontology Based Model for Technology Foresight," in 2008 Third International Conference on Convergence and Hybrid Information Technology, 2008, vol. 1, pp. 510-514.

[40] J. Voros, “A generic foresight process framework,” Foresight, vol. 5, no. 3, pp. 10-21, 2003.

[41] A. Hines and P. Bishop, Thinking about the Future:Guidelines for Strategic Foresight. Washington, DC: Social Technologies LLC, 2007.

[42] W. L. Schultz, "The cultural contradictions of managing change : using horizon scanning in an evidence-based policy context," Foresight, vol. 8, no. 4, pp. 3-12, 2006.

[43] Ma, “In Wikipedia. Retrieved April 10, 2017, from https://en.wikipedia.org/wiki/Ma_(negative_space).” .

[44] Netocracy, "In Wikipedia. Retrieved April 22, 2017, from https://en.wikipedia.org/wiki/Netocracy." .

[45] A. Bard and J. Soderqvist, NETOCRACY: The New Power Elite and Life After Capitalism. Stockholm: Pearson Education, 2002.

[46] M. Hauben, "Preface: What is a Netizen." pp. ix-x, 1995.

[47] M. Lee, “Futurists and futurizens," no. July. pp. 1-3, 2013. 